\title{
ELICITING CHILDREN'S EXPECTATIONS FOR HAND PROSTHESES THROUGH GENERATIVE DESIGN TOOLS
}

\author{
Dursun, Melis; \\ Şener Pedgley, Bahar \\ Middle East Technical University
}

\begin{abstract}
When designing assistive devices for children with disabilities, designers mostly consider technical and functional aspects and overlook factors that affect their usage from children's perspective. Therefore, in most cases, assistive devices do not fully meet the needs of the children and may create a negative effect on children's well-being. To explore the opinion's of children using 3D printed hand prosthetics in Country-Xx, individual generative sessions were conducted with four children with limb deficiency. Generative tools are used to engage children and encourage them to express themselves in relation to prosthesis use. The main aim was to investigate how children provide design relevant information that may help designers to achieve improved assistive devices that support children's physical, emotional and social wellbeing. Children's feedback related to prosthetic usage categorized under two topics; expectations of children for prosthesis use and children's priority expectation for the prosthesis. The findings are argued to be useful and usable by NGOs, product designers and design researchers who work with children with disabilities.
\end{abstract}

Keywords: Participatory design, Inclusive design, Design methods, design with children, prosthesis design

\section{Contact:}

Dursun, Melis

METU

Industrial Design

Turkey

melis.dursun@metu.edu.tr 


\section{INTRODUCTION}

Today, 7 to 22 per 10,000 children are born with limb malformations (Aucourt et al., 2012). Congenital limb malformations have critical impact on the mental and physical development of children from the early stages of their lives to adulthood. Although assistive devices are developed to reduce such negative effects, it is still difficult for children to express themselves about the difficulties or situations that affect them. Lukash and Coles (2002) state that children with such disabilities often cannot sufficiently express their feelings and emotions about physical problems that are affecting them. Therefore, when designing for children, designers tend to investigate children's needs through parents, family members or sometimes teachers instead of directly talking to them (Druin, 2002). Nevertheless, the life of a child with disabilities, in terms of their needs, concerns and experiences can be significantly different from adults' assumptions which make it challenging to bring an empathic understanding (Frauenberger, 2012). Nevertheless, children are generally more competent than they acknowledged by adults and by designers (Hussain, 2012). In this context, a participatory design approach has been an essential concept while designing for and with children, as traditional data collection methods for adults may not be fully suitable for children (Druin, 1999). According to Hussain (2012), generative tools, as part of participatory design methods, are crucial for designing with children because they facilitate both verbal and non-verbal forms of communication, with the use of visual materials. Through such tools, even non-designers can be encouraged to express their needs and dreams, which can serve as inspirations for designers. This paper presents the findings of generative design sessions carried out with four children with upper limb deficiencies. The aim was to investigate how design relevant information, that will help designers to design better assistive devices that support children's physical, emotional, and social wellbeing, can be collected from children. The authors proposed a set of generative tools for encouraging children to express their current experiences with their prosthetics, which helped children to talk about their frustrations, unmet needs, ideas, and dreams. The findings are argued to be useful and usable by NGOs, product designers and design researchers who work with children with disabilities.

\section{DESIGN FOR AND WITH CHILDREN}

There has been extensive research over the years about childhood studies, children's education, pedagogy, development, sociology, and psychology. Historically, children were seen as incompetent, unreliable and even incomplete (e.g., Barker and Weller, 2003) until the UNCRC (United Nations Conventions on the Rights of the child) has declared that children have the right to have a voice in adult socialization. Then, with the emergence of new social studies of childhood (James et al., 1998), children have started to be viewed as experts in their own lives (e.g., Lewis et al., 2004; Mauthner, 1997). In research contexts, children's roles also transformed from being the subjects of a study to research partners (Greig, Taylor and MacKay, 2013; Christensen and James, 2008). There has also been a change of mindset from 'on children' to 'with children' whilst conducting research. That meant better understanding of what is important and meaningful to children from their perspectives (Clark, 2007). Besides, the concept has required the emergence of participatory research methodologies to complement traditional methods like observation and questionnaire (Punch, 2002). Similarly, as Scott (2008) suggests adopting different forms of communication is necessary while working with children

due to their limitations of language use, literacy, and different stages of cognitive development. To bridge these social and communicative distances, Baek and Lee (2008) noted that generative design tools attract children's interest, makes it easy to include them in cognitive activities and helps them to overcome their shyness when they are with adults. As with any non-designer participant, children cannot be expected to have the skillset that of a designer, but generative tools and techniques are developed to include them in the design process (Druin, 2002). Generative tools refer to application materials of participatory design methods, and these materials serve as a starting point for designers while facilitating children's (in this case) expressions about their needs and dreams (Hussain, 2012), articulating children's past, present and future experiences (Sanders, 2001). According to Hussain (2012), rather than the information given by the user that expressed user's needs, a shared understanding through the dialogue between the designer, user and the artefact created with these tools are valuable in the process. 


\section{UPPER LIMB DEFICIENCY IN CHILDREN}

The primary cause of upper limb deficiencies in children is congenital, majority of which is transracial (Wright et al., 2001). In terms of enabling the children to achieve maximum functional ability and independence in the social context, rehabilitation is necessary (Burger, Brezovar and Marinček, 2004). Most children with limb deficiency rely on an assistive device depending on their deficiency level for performing daily activities (Wright et al., 2001). Prosthetics for children are developed for reducing their physical limitations and support their social and physical growth (Davidson, 2002). According to Burger, Brezovar and Marinček (2004), independence of the children can only be achieved by using prosthetic or assistive devices. However, prosthetics usage in children is not recommended because they should be replaced frequently due to children's constant growth (Burger, Brezovar and Marinček, 2004). Besides, the complexity of prosthetic usage requires a particular approach for children's development. Accordingly, Synder (1975) argues that children's specific needs should determine the approach to congenital malformation. Emotional and aesthetic needs are essential motivation factors for using an assistive device (Murray and Fox, 2002). As children's self-image is developing, when designing assistive devices for children, such needs should also be considered. There are studies on technical aspects of prosthetics (Glynn et al., 1986, Pruitt et al., 1997, Ccorimanya et al., 2019) but there is a scarcity of research published on factors that affect prosthetic usage from children's viewpoint.

\section{FIELDWORK, SET-UP, AND PROCEDURE}

[an anonymized] is one of the countries where the use of a prosthesis for children is not encouraged due to their continual growth. A few years ago, an NGO based in Country-X, started to provide children in need with relatively low-cost, mechanical 3D printed prostheses with a grasping function controllable by elbow and wrist movement. Although, the functionality of the prosthetics is limited, they can provide rehabilitation for muscles until children complete their physical growth. The study presented in this paper was carried out as individual sessions with four children who use the 3D printed prosthetic devices provided by the NGO. It is a partner of a wider online digital global community called 'Enabling the Future' (e-NABLE, 2020) bringing together 'digital humanitarian' volunteers from all over the world who are using their 3D printers to make free and low-cost prosthetic upper limb devices for children and adults in need. Therefore, the sessions aimed to explore the children's concerns with their 3D printed prostheses and encourage them to share the difficulties they encounter and express their dream prosthesis. The information collected from children believed to show directions to designers about what they should take into consideration to better answer children's expectations for future prosthesis.

\subsection{Participant Sampling}

Children participants were selected among the NGO's contacts, in which the first author has been working on a voluntary basis for four years and had known the children and their families in person. Since they have known each other, it made it easier for the author to approach children and their families, explain the purpose of the research, and ask whether they would be interested in participating. Consequently, four children were secured: three female and one male the ages ranged between 8-12. All four children have congenital limb deficiency, and all of them have been using a personalized 3D printed prosthetic hand that the NGO provided them. Figure 1 shows the demographics of the children, and for research purposes, all children are assigned with a made-up name. 


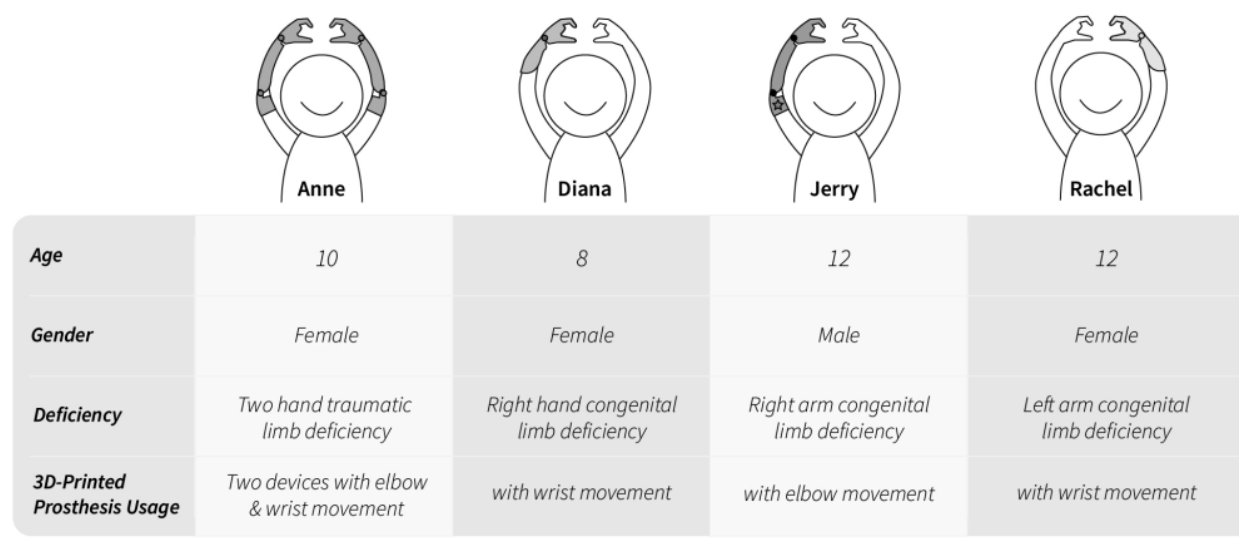

Figure 1. Demographics of the children

\subsection{Data Collection Materials: 'Child's Prosthesis Co-design Toolkit'}

For the planning of what design approach and accompanying methods, tools, and techniques to use for engaging non-designers (i.e., children in this study) in the design process, Sanders (2010) proposes a framework that includes three dimensions: form, purpose, and context. Accordingly, form is "a kind of action that is taking place between the participants in an activity, and is categorized as making, telling or enacting". Purpose can include four usages as for: 1) probing participants, 1) priming participants to immerse them in the domain of interest, 3) better understanding the participants' current experiences, and 4) generating ideas or design concepts for future. Context can be described as "where and how the tools and techniques are used" and classifies along these four dimensions: group size and composition, face-to-face vs. online, environment, and stakeholder relationships. As stated by Sanders (2010), it is important to understand the objectives of a study and then customize these dimensions accordingly. Depending on the purpose, content of the tools and the context it is going to be applied can vary. Hence, different techniques can be used, such as image-cards as they can be sorted, categorized, prioritized, or utilized for opening up people to conversations. According to the framework, 2D mappings and cards are selected as tools facilitate information sharing and idea generation based on children's own reflections. Conducting the sessions with each child individually was found reasonable in terms of exploring the differences of the children's needs and expectations. In the light of this framework, selected tools were designed and reinterpreted according to the objectives of the components and, 'Child's Prosthesis Co-design Toolkit' was developed, which consists of the following components: i) daily activity journey; ii) personal 3D-printed prosthesis evaluation; iii) image sorting cards; iv) dream prosthesis map; and v) ideation space. The tool has gone through several design iterations with children. In this paper, only 'image sorting cards' and 'dream prosthesis map' will be presented, as the development of the tool and the other components that are not introduced are outside the scope of this paper.

Image Sorting Cards: To elicit children's expectations related to prosthesis usage, image cards were prepared. For the activity, the set of ten internet sourced prostheses images were organized according to four style-categories: 3D printed, futuristic, hobby centred and electronic (see Figure 2). Children are expected to classify these images into their 'likes' and 'dislikes' and encouraged to reflect on (the blank cards that they were given) what aspects specifically they like and vice versa.

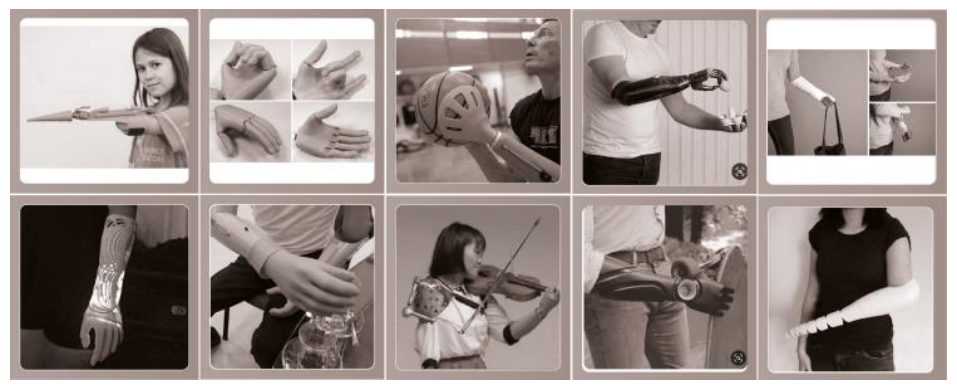

Figure 2. A set of ten hand-prostheses image sorting cards 
Dream Prosthesis Map: After deriving children's reflections on the prosthesis, based on the aspects they like and dislike, it was important to understand the importance of each of the expectation they mention. Dream Prosthesis Map includes concentric circles with an illustration of the hand-prosthesis at their centre (see Figure 3). The closest circle to the centre represents the most critical expectation for the children, the outer circles gradually represent less important ones. The child is expected to place the expectation cards on the map according to their personal significance and priority.

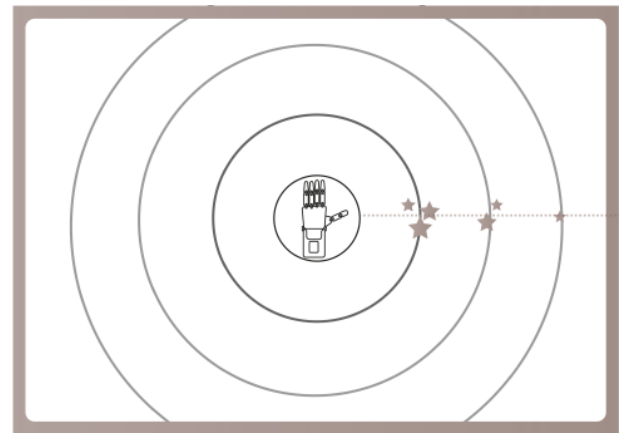

Figure 3. Dream Prosthesis Map for card sorting activity

\subsection{Data Collection Procedure}

Creating a comfortable atmosphere for children is essential to comfortably express their ideas and thoughts with the researcher. In order to eliminate other family members' inferences (e.g., especially the participants' little brothers or sisters) individual sessions were carried out at the researcher's office. Each child was invited with an accompany (e.g., parent, older sister/brother etc, however the companion is kindly asked to wait outside. The sessions were carried out individually.

The session started with a short icebreaker activity and aim of the study is introduced. Then a child was asked for her/his verbal consent, and five brief activities (i.e., i/daily activity journey; ii/personal 3D-printed prosthesis evaluation; iii/image sorting cards; iv/dream prosthesis map; v/ideation space) that will take place in the session were explained. For the scope of the paper, only the activities 'iii' and 'iv' will be explained. The child was reminded that he/she was free to express himself/herself with different materials (e.g., drawings, collages, play-doh etc.). Then, 'image sorting' activity started. After studying the Image Sorting Cards, the child children were asked to sort them into the 'likes' and 'dislikes', then was asked to state the reasons for the likes/dislikes. This activity resulted in several post-it notes filled in with keywords by the child. The intentions were: to direct children to define their own expectation for hand-prosthesis hence, to elicit design-relevant expectation while helping them to visualize their dream prosthesis. On completion of the first activity, the child was invited to indicate priorities within his/her proposed expectation by making use of the Dream Prosthesis Map. When the remaining activities were completed, the child was thanked for his/her contribution and explained how this contribution would help designers to improve their future hand-prosthesis designs.

\section{RESULTS AND ANALYSIS}

\subsection{Data Analysis}

All data collected through Image Sorting Cards, and Dream Prosthesis Map are content analysed. In both cases, occurring themes were created with deductive coding, after several rounds of data organisation main and subheadings are created. Image Sorting Cards helped to achieve prosthesis expectation of the children; and Dream Prosthesis Map provided insightful information about children's priority expectations about prosthesis usage. Results will be presented under the relevant sections.

\subsection{Expectations of Children for the Prosthesis Use}

Analysis led to the expectations for prosthesis of the children, organised in two categories: 'pragmatic expectation', which refers to functionalities that the child prosthesis delivers; and, 'hedonic expectation', which refers to social, aesthetic, intangible and subjective dimensions affecting the children's concept of the prosthesis. The expectation has emerged from all four children's common concerns related to prosthesis usage, but child-specific variations can be found under each expectation. 


\subsubsection{Pragmatic Expectation of Children Regarding the Prosthesis Design}

Pragmatic expectation, that are expressed in the form of product (prosthesis) design attributes by children, can be divided into four headings: a) usability, b) functionality, c) physical comfort, d) durability.

Usability: Expectation for the usability have arisen from two sub-themes as: effectiveness and ease of control. All four children stated different aspects of usability related expectation in the narrations. The children expressed their concerns related to controlling the prosthesis and stabilizing the objects. To illustrate, Anne reflects her expectation for grasping objects without slipping with her 3D printed prosthetic hand as: "The hand you gave slips while holding something. If I could hold something tight, I might feel comfortable. While holding something, I want to hold without worrying."

On the other hand, 'ease for control' was stated in the participants' statements for representing the physical effort needed while performing an activity. According to the results, the current prosthetic devices of the children required constant effort while grasping objects, therefore, it causes pain on muscles after a while. For instance, Diana expressed the difficulty she has encountered during her 3D prosthetic hand as: "When I bend my wrist for a while, my arm hurts."

Functionality: This heading was constructed on two subheadings: usefulness and multifunctionality. 'Usefulness' is one of the most stated expectation of the functionality. Children expect a prosthesis to being useful for daily activities. Rachel also expressed the importance of functionality of her prosthesis usage in the following statement: "Usefulness is so important, after all, if it is not useful, I would not use the prosthesis." 'Multifunctionality' which refers to using the prosthesis for different activities certainly increases the prosthesis's daily usage was highlighted by all the children. The children mentioned two dimensions related to the multifunctionality of the prosthesis; the ability to grasp different objects and the ability to make precise movements. For instance, Anne explained her expectation regarding doing different activities with her dream prosthesis as: "I want hands that help me for different activities. There will be one hand that enables me to hold everything on and do everything." Jerry, Diana, and Rachel expressed that they face difficulties while doing precise movements with their current $3 \mathrm{~d}$ prosthetic hands. It is also associated with ease of control in terms of controlling the prosthesis while grasping. For example, Diana commented on a prosthesis visual, which holds an egg (Figure 4):

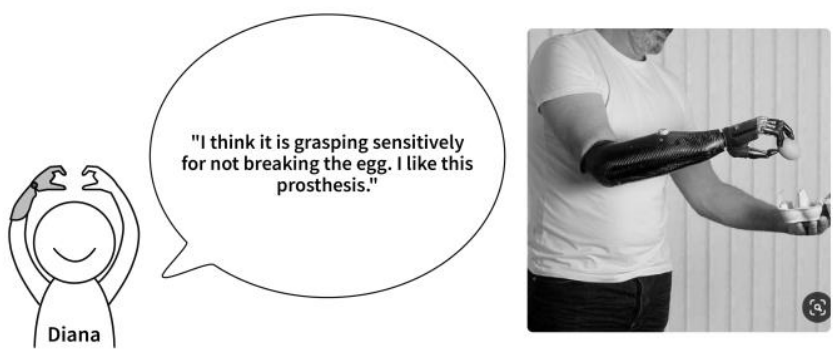

Figure 4. Diana's comments on the prosthesis image

Physical Comfort: Another expectation mentioned by children is 'physical comfort'. In this context, comfort is used for the physical dimension of the prosthesis and in contrast to discomfort. All four children described their experiences with their prosthetic hands with feelings of discomfort, which is mainly associated with pain, soreness, and numbness. Diana explained the expectation for comfort in use and comfort of straps of the prosthesis: "It hurts my arm when I use it too much. If it does not hurt, I would always wear it." In addition, Rachel expressed the difficulties related to perspiration while wearing a prosthesis hand: "I do not want my arm to get sweaty inside the prosthesis. It would be better not to sweat. "

Durability: According to the children, 'durability' refers to long-term usage of the prosthesis. Also, the durability of the prosthesis strongly connected with reliability. In that sense, the durability was constructed on two dimensions, shape and form and material durability. According to the children, shape and form is essential to consider for achieving a durable prosthesis. To illustrate, Jerry evaluates the durability of the prosthesis image considering its shape and form (Figure 5): 


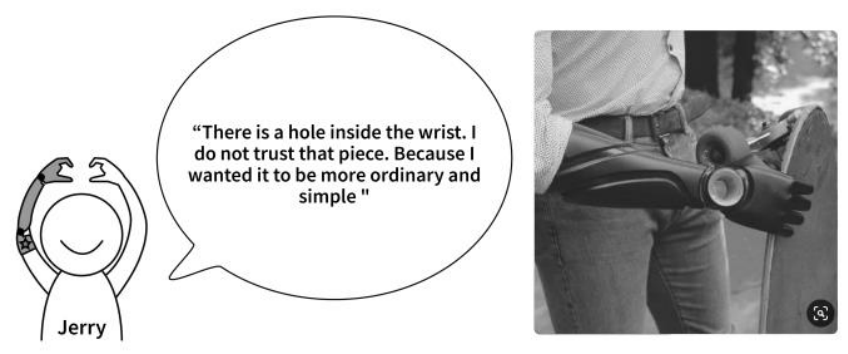

Figure 5. Jerry's comments on the prosthesis image

Material durability is another common stated expectation. While talking about a prosthesis, Diana showed us her old prosthetic hand: "I did not use it much, but these strings were corroded. It was working, but now it is not." On the other hand, external factors cause the need for frequent repairs of the materials. The participants' responses indicate the need for frequent repairing cause frustration and negatively affect the motivation of children for prosthesis usage. To illustrate, Jerry stated these are the reasons behind his dissatisfaction regarding his prosthetic device: "The reason why I do not use my $3 D$ printed prosthetic hand is that it breaks down easily and those strings can break off easily. It requires frequent repair, and I am so bored with this. In the end, I will ask permission from you to print the prosthetic hand myself. "

\subsubsection{Hedonic Expectation of Children Regarding the Prosthesis Design}

Hedonic expectation formed on the basis of five experiential aspects from the children's point of view: aesthetic appeal, reliability, other people's views and hobby-specific usage. These expectations are stated by the children; however, its link with attributes of prosthesis design is different from child to child. To illustrate, the children's aesthetic appeal refers to the children's design preferences regarding personal interests and opinions that reflect on their prosthesis expectations. For instance, Anne and Rachel expressed her subjective admiration on a prosthesis visual (Figure 6):
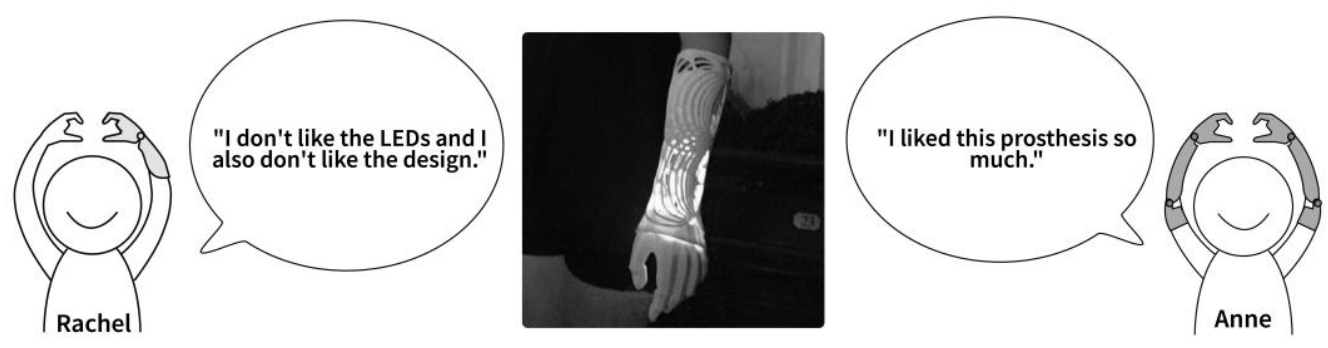

Figure 6. Rachel and Anne's comments on the prosthesis image

All four children emphasized the value of reliability in the prosthesis experience. They expressed their expectations for using the prosthesis without worrying about its performance. In addition, life-like prostheses have advantages in comparison with other types of the prosthesis from children's views. All children looked positively the visuals of the life-like prosthesis and two of them associated lifelike appearance with reliability of the prosthesis. Also, the preferences regarding prosthesis are affected by other people's views. In early ages, these other people are family and parents while later ages children start to pay attention to her friends and acquaintance's opinions: Rachel: "It has to be cool. When I show it to my friends, they should say "wow!'. Anne: "When someone looks at my hands or me, I like it very much. I do not like it when they look at my own hands, but when they look at the prosthesis and say, "oh so beautiful", I am pleased." The hobby-specific usages have a significant influence on children's motivation for using the prosthesis. Results of the analysis showed that hobby specific prostheses, whether it is their hobby or not, are considered as usable, functional, and attracted by the children. To illustrate, Diana mentioned about her view on the possible social advantages of the hobby specific prostheses: "I wish I had an assistive device for playing the violin. I would participate in violin competitions and I would have so many friends." 


\subsubsection{Children's Priority Expectation for the Prosthesis}

Priorities were arisen for presenting the importance of a user-defined expectation. The study shows that along with the differences in perspectives and deficiencies, priorities may differ from child to child in the context of prosthesis design. Therefore, the priorities of the expectations will be explained for each participant's perspective.

- Anne: Due to the level of her deficiency (two-hand), Anne emphasized functionality and usability related expectations in a card sorting activity. From her point of view, multifunctionality and effectiveness are the most important expectations that a dream prosthesis fulfils. Aesthetic appeal and durability of the material are a secondary priority from her perspective. Lastly, she stated using for hobbies and other people's views are the expectations that she wants her prosthesis has, but they are not as much as necessary with other expectations.

- Diana: Diana expressed that she could not compare her expectations in terms of significance, and all of them are so important for her. Therefore, durability, hobby specific usage, ease of control, multifunctionality, other people's views, aesthetic appeal, comfort in use is the most important expectations for her dream prosthesis.

- Jerry: Jerry mentioned three essential expectations that his dream prosthesis should have; aesthetic appeal, hobby specific usage and reliability. His primary priorities based on hedonic expectations as categorized in the results of the study. The durability, effectiveness and multifunctionality are reflects his secondary priorities for the prosthesis usage. Moreover, other people's views, aesthetic appeal are the least essential expectations from his perspective.

- Rachel: Comparing to other children, Rachel emphasizes on expectation related to "aesthetic appeal and other people's views", other expectations are strongly associated with these two expectations for her. She placed her expectations related to the aesthetic appeal, other people's views, ease of control and multifunctionality on the centre of the map to represent her primary expectations. Hobby specific usage is placed as a secondary priority.

\section{DIscussion}

\subsection{Implications for Design}

The results represent common patterns in expectations related to product use and differences in children's priorities regarding these expectations. In order to increase satisfaction with the overall experience, designers should consider children's perspectives regarding product use and differences between the perspectives of the children, instead of presenting one fits for all approach. To design better assistive devices which may fulfil children's expectations, the following points can be listed as generalizable inferences:

- Due to a lack of muscle development, children experience difficulties while controlling the bodypowered prosthesis. This cause concerns in children related to the reliability of the prostheses for performing certain activities (e.g., holding or carrying objects). Therefore, the effort needed to use the prosthesis while performing such activities should be at a minimum. Also, it should be designed with the child's age and deficiency level in mind.

- Children with upper limb deficiencies face barriers in participation in many activities and events. Therefore, supporting children in improving their skills through an assistive device is essential for children's both physical and social well-being. The design of the prosthesis should allow children to perform a wide range of activities, multifunctionality should be taken into consideration. The durability of the materials, design contribute to enabling children to accomplish different activities in different contexts, as well as supporting long-term usage.

- For children, a prosthetic hand is not only a physical tool that helps them in daily activities, but it is also a social instrument that represents the child's identity. Therefore, visual aesthetics should be considered as a tool for the social integration of children. Aesthetic appeal, age appropriateness, novelty and customizability should be considered to help children to be more confident to get involved in society without hesitating about their deficiency.

\subsection{Implications for the Methodology}

Describing the objectives of the study and the role of the participant and explaining their participation is valuable for the study was to increase the willingness of the participants. The generative methods and 
tools were easy to follow by children. All were comfortable while expressing their opinions and preferences and took initiatives in ranking the expectations activity while pointing out their priorities. Providing ways of expressing themselves, generative tools relieve children from the stress of verbal communication. Writing was optional for the participants; some of them preferred the researcher to write their expectations on the blank cards. Since children have experience with 3D printed prosthetic devices, previous experiences with their current device limited their comments regarding prosthesis visuals. Besides, since children did not have a chance to use the prosthesis on the images, findings mostly based on visual stimuli and the context of the image. To illustrate, while commenting on a prosthesis image, Anne evaluated the prosthesis according to the function represents on the image, however, when asking more profound questions, she stated: "I would not use it if it cannot keep an egg. It is huge, and it may be heavy." Children tended to use abstract verbal expressions such as "I like the prosthesis; it looks nice." Therefore, asking questions for better understanding the meaning behind the expression is necessary. Alternatively, generative design tools allow to initiate discussions for challenging topics. As a strategy, for the difficult topics, alternative responses were presented to children in order to both clarify the question and facilitate to express their ideas about the difficulties that they experienced.

\section{CONCLUSIONS}

The overall aim of this study was to explore how encouraging children to express their disability can enrich the process of prosthesis design to fulfil the expectations of the user itself. This study presents the generative research and its design implications and the advantages and constraints of the methodology. As mentioned before this is a part of a bigger research conducted with the children. Child's Prosthesis Co-design Toolkit proved to be useful to gather insights for supporting the design process. Reflections of the children were collected and categorized under two headings: pragmatic and hedonic expectations. The children defined expectations related to these categories were discussed for providing input for the process of prosthesis design. The outcomes of the study believed to be a useful guide for designers, who work on child prostheses. Finally, a reflection for including children with disabilities in the design process with generative design tools are as follow.

- Children tend to say what adults want to hear. Children tended to hesitate to talk about difficulties related to their 3D printed prosthetic hands due to the first author's role in the NGO who gave them these prosthetic hands. Therefore, explaining the aim of the study and the value of children's participation should be explained while researching with children.

- Abstract and ironic expressions can be given by children. Some children gave conflicting expressions while sharing their opinions related to prosthesis images. For better understanding, the actual construct behind the words, more in-depth questions can be asked for these kinds of situations.

- Giving children free space to express themselves is necessary. It is important to inform children about their role in the generative session. In the generative sessions, children were asked to participate in activities as a design partner and were informed about their participation's importance for the study.

- $\quad$ Some task-based activities may be hard to carry out for children with limb deficiency. While working with children with limb deficiency, it is essential to design tools that are proper for their physical capabilities with the consideration of their deficiency type. In the generative sessions, some children had difficulties while writing. The first author offered help for writing-based tasks.

- Generative design tools have potential to broaden children's horizon. These children are not usually given a voice for expressing their opinions, feelings, and dreams about their deficiencies. Some of the children expressed their happiness for participating in the research study. Also, some of them expressed they had never thought about prosthesis of their dreams.

As the next stage of the present study, integrating children into designing phase with utilizing the information they provide in this study and exploring the possible benefits of participatory design on the children with limb deficiency is planned. Discovering the possible ways to understand the relationship between positive psychology and prosthesis experience of children is also part of the future study objectives. 


\section{REFERENCES}

Aucourt, J. et al. (2012) "Congenital malformations of the hand and forearm in children: What radiologists should know”, Seminars in Musculoskeletal Radiology, 16(2), pp. 146-158. https://dx.doi.org/10.1055/s-0032-1311766.

Baek, J.-S. and Lee, K.-P. (2008) "A participatory design approach to information architecture design for children”, CoDesign, 4(3), pp. 173-191. https://dx.doi.org/10.1080/15710880802281026.

Barker, J., and Weller, S. (2003) “"Is it Fun?” Developing Children Centred Research Methods', International Journal of Sociology and Social Policy, 18(1), pp. 19-28. https://doi.org/10.1108/01443330310790435.

Burger, H., Brezovar, D. and Marinček, С̆. (2004) "Comparison of clinical test and questionnaires for the evaluation of upper limb prosthetic use in children”, Disability and Rehabilitation, 26(14-15), pp. 911-916. https://dx.doi.org/10.1080/09638280410001708931.

Ccorimanya, L., Watanabe, R., Hassan, M., Hada, Y., and Suzuki, K., (2019) “Design of a myoelectric 3D-printed prosthesis for a child with upper limb congenital amputation", Annual International Conference of the IEEE Engineering in Medicine and Biology Society. pp. 5394-5398. https://dx.doi.org/10.1109/EMBC.2019.8857899.

Christensen, P., and James, A. (2008). "Research with children: Perspectives and practices." Routledge. http://www.ufri.uniri.hr/files/\%C4\%8Dasopis/casopis_br_5.pdf\#page=103

Clark, A. (2007). "A hundred ways of listening: Gathering children's perspectives of their early childhood environment." YC Young Children, 62(3), 76.

Davidson, J. H., Jones, L. E., Cornet, J., and Cittarelli, T. (2002) "Management of the multiple limb amputee", Disability and Rehabilitation, 24(13), pp. 688-699. https://dx.doi.org/10.1080/09638280110115384.

Druin, A. (1999) “Cooperative inquiry: Developing new technologies for children with children”, Conference on Human Factors in Computing Systems - Proceedings, pp. 592-599. https://dx.doi.org/10.1145/302979.303166.

Druin, A. (2002) "The role of children in the design of new technology, Behaviour \& Infirmation Technology", Behaviour \& Information Technology, 21(1), pp. 1-25. http://legacydirs.umiacs.umd.edu/ allisond/child_info_tech/Druin-BIT-Paper2002.pdf.

e-NABLE, (2020). "Enabling The Future." [online] Available at: <http://enablingthefuture.org/>.

Frauenberger, C., Good, J. and Alcorn, A. (2012) "Challenges, opportunities and future perspectives in including children with disabilities in the design of interactive technology", ACM International Conference Proceeding Series, pp. 367-370. https://dx.doi.org/10.1145/2307096.2307171.

Greig, A., Taylor, J. and MacKay, T. (2011) "Designing and Doing Research with Children: The Importance of Questions", Doing Research with Children, pp. 78-97. https://dx.doi.org/10.4135/9781849209045.n5.

Glynn, M. K., Galway, H. R., Hunter, G., \& Sauter, W. F. (1986). "Management of the upper-limb-deficient child with a powered prosthetic device." Clinical orthopaedics and related research, (209), 202-205.

Hussain, S. and Sanders, E. B. N. (2012) "Fusion of horizons: Co-designing with Cambodian children who have prosthetic legs, using generative design tools", CoDesign, 8(1), pp. 43-79. https://dx.doi.org/10.1080/15710882.2011.637113.

James, A. (1998) "Foreword", in I. Hutchby and J. Moran-Ellis (eds) Children and Social Competence, pp. vii-x. London: Falmer Press.

Lewis, V., Kellett, M., Robinson, C., Fraser, S., \& Ding, S. (Eds.). (2004). "The reality of research with children and young people." Sage.

Lukash, F. N. (2002) “Children's Art as a Helpful Index of Anxiety and Self-Esteem with Plastic Surgery”. Plastic and Reconstructive Surgery, pp. 1777-1786. https://dx.doi.org/10.1097/00006534-200205000-00001

Mauthner, M. (1997) "Methodological aspects of collecting data from children: Lessons from three research projects", Children and Society, 11(1), pp. 16-28. https://dx.doi.org/10.1111/j.1099-0860. 1997.tb00003.x.

Murray, C. D., and Fox, J. (2002). "Body image and prosthesis satisfaction in the lower limb amputee". Disability and rehabilitation, 24(17), 925-931. https://doi.org/10.1080/09638280210150014

Punch, S. (2002) "Research with children: The same or different from research with adults?", Childhood, 9(3), pp. 321-341. doi: 10.1177/0907568202009003045.

Sanders, E. B.-N. (2001) “A New Design Space”, ICSID 2001 Seoul: Exploring Emerging Design Paradigm, Oullim. 7-11, pp. 317-324.

Sanders, E. B. N., Brandt, E., \& Binder, T. (2010, November). "A framework for organizing the tools and techniques of participatory design." In Proceedings of the 11th biennial participatory design conference pp. 195-198, https://doi.org/10.1145/1900441.1900476.

Snyder, C. C. (1975). "Congenital deformities of the hand and forearm.” Plastic and Reconstructive Surgery, 56(4), 445-446.

Pruitt, S. D., Varni, J. W., Seid, M., \& Setoguchi, Y. (1997). "Prosthesis satisfaction outcome measurement in pediatric limb deficiency”. Archives of physical medicine and rehabilitation, 78(7), 750-754, https://doi.org/10.1016/S0003-9993(97)90084-8.

Wright, F.V., Hubbard, S., Jutai, S., and Naumann, S. (2001). "Development and reliability testing of a new functional status questionnaire for children who use upper extremity prostheses", Journal of Hand Therapy, Pages 91-104, https://doi.org/10.1016/S0894-1130(01)80039-9. 